\title{
Demonstration of Intramuscular Artery and Nerve Distribution in the Same Whole Mount Gracilis Muscle by Different Colors
}

\author{
Demostración de la Distribución Intramuscular de la Arteria \\ y Nervio del Músculo Grácil Mediante Diferentes Colores
}

\author{
Xiaochun An*; Pengfei Dong**; Xiangyang Qu* \& Shanhui Li*
}

\begin{abstract}
AN, X.; DONG, P.; QU, X. \& LI, S. Demonstration of intramuscular artery and nerve distribution in the same whole mount gracilis muscle by different colors. Int. J. Morphol., 34(3):1034-1038, 2016.

SUMMARY: The goal of this study was to describe the intramuscular artery and nerve distribution in detail by different colors in the same whole mount gracilis muscle. Red latex injection into the external iliac artery was performed on 14 fresh human cadavers. Two weeks later, 28 gracilis muscles were harvested from the cadavers and during this course the number of the arterial pedicle of each specimen was counted. Then, the muscle specimens were fixed in $10 \%$ formalin 4 weeks for fixation and Sihler's staining procedures was performed on each muscle specimens. After all of the procedures, the gracilis muscle appeared almost transparent, and the extra- and intramuscular artery and nerve branches, even the terminals, were clearly demonstrated in red and dark blue separately. Two of the 28 specimens were supplied by a single main arterial pedicle alone, 14 specimens by a main arterial pedicle and an accessory pedicle, 8 specimens by a main pedicle and 2 accessory pedicles, while 4 specimens by a main arterial pedicle and 3 accessory pedicles. Although the number of the arterial pedicles was inconsistent, the intramuscular artery branches anastomosed with each other and formed a whole arterial system in all specimens. The nerve innervating the gracilis muscle divided into two or three major branches, which directed distally and innervated the distal two thirds of the muscle, while running longitudinally and parallel to the muscle fibers. We found the innervation pattern was remarkably consistent from specimen to specimen. This study provided very detailed and useful information for anatomists, physiologists and reconstructive surgeons. Furthermore, we here also provided a new method to demonstrate the intramuscular artery and nerve distribution in the same whole mount muscle by different colors for other researchers to refer to.
\end{abstract}

KEY WORDS:Intramuscular Distribution; Artery; Nerve; Gracilis Muscle.

\section{INTRODUCTION}

The gracilis muscle is widely utilized by plastic and reconstructive surgeons in a variety of applications as a pedicled muscle or for free functioning muscle or flap transfer (Krimmer et al., 1995; Melenhorst et al., 2008; Taylor et al., 2003; Zuker et al., 2011). Accurate knowledge of the muscle architecture, particular the intramuscular innervation patterns and arterial distribution, is critical for guiding the muscle flap design and innovation, such as the design for the coverage of two anatomically distant wounds and for the reconstruction of facial paralysis (Manketlow \& Zuker, 1984; Schoeller et al.). When the gracilis muscle is used for the coverage, this muscle should be split transversely into two free flaps (Schoelle et al.). In the reconstruction of facial paralysis, because the transfer of the entire gracilis muscle would give a more powerful movement and a greater bulk than necessary, only a small piece of the muscle is required (Revenaugh \& Byrne, 2015). In these cases, the clinician must know precisely the intramuscular anatomy of the muscle to preserve the arterial supply and innervation of this muscle flap in order to confirm its survival and function. Also, precise acknowledge of the intramuscular distribution of artery and nerve can prompt an improvement of ideal muscle flap design without harming its functional integrity.

The basic anatomy of the gracilis muscle, especially its extramuscular blood supply and its innervation, has been well and extensively documented and understood in the past (Magden et al., 2010; Tayler et al.). The intramuscular arterial pattern has also been outlined by methods of angiography or micro-dissection (Morris \& Yang, 1999), while the intramuscular innervation distribution by Sihler's staining 
(Won et al., 2012). Unfortunately the methods of angiography or micro-dissection cannot demonstrate the detailed information of the intramuscular arterial distribution thoroughly because of their disadvantages and inabilities, for example, small blood vessels cannot be traced. Although Sihler's staining, with more strengths, is a whole mount nerve staining technique and the only method available for mapping the entire intramuscular nerve, studies of the intramuscular correlation of the vascular and neural patterns, especially demonstrated in the same whole mount human muscle by different colors, is still lacking in the literature.

Inspired by the information from Mus paper $(\mathrm{Mu} \&$ Sanders, 2010), we developed a method to simultaneously demonstrate the intramuscular artery and nerve distribution by different colors in the same whole mount muscle based on the Sihler's staining technique. Using this method we have successfully finished the human gracilis muscle showing the intramuscular artery branches by red and the nerve branches by dark blue. The purpose of the current study was to document comprehensively the intramuscular artery and nerve distribution of the gracilis muscle, with particular emphasis on the anatomic information required for segmental division of the muscle by clinicians. And we also simply referred to our method hoping for providing a useful procedure for researchers who want to investigate the intramuscular artery and nerve distribution in the same whole mount muscle.

\section{MATERIAL AND METHOD}

Fourteen fresh cadavers (8 males and 6 females) with an average age of 64 years (range 54-76 years) were carefully selected to ensure that these human bodies suffered no diseases, such as occlusion of artery or diabetes, which may affect blood vessels or nerves. Red latex was injected into the external iliac artery $2 \mathrm{~cm}$ above the inguinal ligament. Two weeks later, 28 gracilis muscles were harvested from the cadavers and during this course the arterial and neural pedicles were carefully protected. The number of arterial pedicles of each gracilis muscle was counted. Then the muscles were placed in $10 \%$ formalin 4 weeks for fixation. During this period, the connective tissues covering the muscles were carefully removed under an operating microscope (Zeiss OpmiPico, Oberkochen, Germany) to facilitate muscles tissue maceration. The artery and nerve branches were meticulously protected. The muscles were then dyed with modified Sihler's staining (Liem \& van Willigen, 1988; Wu \& Sanders, 1992). Finally, digital photographs of the muscles were taken and intramuscular artery arborization and nerve distribution patterns were recorded.

\section{RESULTS}

After the procedures the gracilis muscle appeared almost transparent, and the extra- and intramuscular artery and nerve branches, even the terminals, were clearly demonstrated separately in red and dark blue. (Fig. 1a \& b).

The gracilis muscles were found to be supplied by one to four arterial pedicles, which entered the deep surface of the muscles near the anterior border of the muscle. Two of the 28 specimens $(7.1 \%)$ were supplied by a single main arterial pedicle alone, 14 specimens $(50.0 \%)$ by a main arterial pedicle and an accessory pedicle, 8 specimens (28.6\%) by a main pedicle and two accessory pedicles, while 4 specimens $(14.3 \%)$ by a main arterial pedicle and three accessory pedicles.

After entering the muscle, the main and accessory arterial pedicles split into transverse, ascending, and descending branches. Furthermore, there were well developed intramuscular vascular anastomoses between the descending branches of the main artery pedicle and the ascending branches of the first accessory arterial pedicles, whereas the intramuscular arterial branches anastomosed in the same way with the accessory arterial branches. In this manner, the intramuscular arterial branches formed a whole body arterial system and we found the anastomosed intramuscular arterial branches laid parallel to the longitudinal muscle fibers. Through this way all the gracilis muscle specimens demonstrated a consistent intramuscular arterial distribution pattern and formed a whole arterial system except for the two specimens supplied by a single main arterial pedicle alone (Figs. 1a \& b).

The motor nerve arose from the obturator nerve and entered the muscle in association with and somewhat proximal to the main vascular pedicle. Before entering the muscle, the nerve divided into two or three major branches directed distally, which innervated the distal two thirds of the muscle. Arising from one of these major nerve branches, one nerve fascicular oriented proximally and innervated the proximal one third of the muscle. After entering the muscle all these major branches subdivided in the distal two thirds of the muscle and the intramuscular nerve branches ran longitudinally and parallel to the muscle fibers, while the intramuscular nerve branches in the proximal one third ran obliquely to the muscle fibers. We found the intramuscular nerve distribution pattern was remarkably consistent from specimen to specimen, although these specimens had different number of artery pedicles (Figs. 1a \& b). 

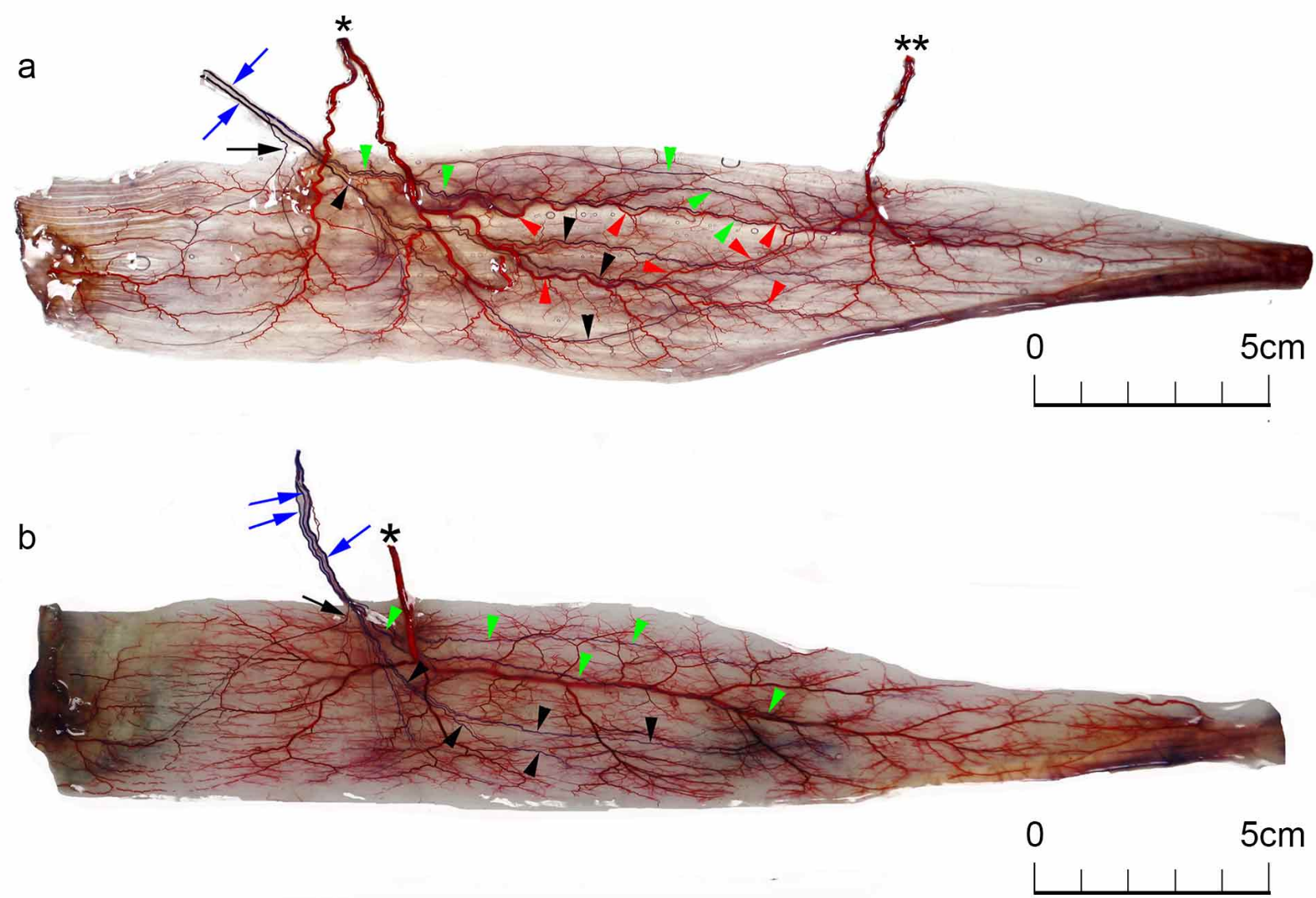

Fig. 1a and b. Demonstration of intramuscular artery and nerve distribution in the same whole mount gracilis muscles Red arrow heads showed after entering the muscle the descending branches of the main arterial pedicle anastomosed with the ascending branches of the accessory arterial pedicle forming a whole arterial system in the muscle. Blue arrow showed that before entering the muscle, the nerve divided into two or three major nerve branches. Black arrow showed that a nerve fascicular arose from one of the major nerve branches and distributed to the proximal one third of the muscle. Green arrow head showed after entering the muscle one of the major nerve branches subdivided and innervated the anterior part of the distal two thirds of the muscle while the black arrow heads showed the one distributed to the posterior part. The $*$ and $* *$ showed the main and accessory arterial pedicles respectively. Although the numbers of the arterial pedicles of these specimens were different, intramuscular nerve distribution pattern was remarkably consistent from specimen to specimen.

\section{DISCUSSION}

Since the basic anatomy of gracilis muscle, such as its physical parameters and arterial and neural pedicle locations, has already been well and extensively explored, we focused on the intramuscular distribution of the artery and nerve branches in this study. Although the intramuscular arterial anastomosis in the gracilis muscle has already been reported by a previous angiographic study (Morris \& Yang), in the current study we more clearly and directly, visually demonstrated the presence of such an arterial system. So, the design of an appropriately sized gracilis muscle flap, based on the main or an accessory arterial pedicle, is possible. The gracilis muscle has already been split transversely or longitudinally into two free flaps for soft tissue coverage of two anatomically distant wounds or for functional reconstruction (Schoeller et al.; Zuker et al.). But in order to finish these procedures, it entails that the gracilis muscle should have at least on accessory pedicle. Cavadas et al., (2004) found no muscle has fewer than two accessory pedicles, whereas Macchi et al., (2008) concluded at least one accessory pedicle was invariably present. However, in this study, two in 28 specimens $(7.1 \%)$ were found to be solely supplied by a single main arterial pedicle alone. This is of clinical importance, because this case certainly affects adversely the usage of the gracilis muscle and precludes the 
possibility of splitting this muscle transversely or longitudinally into two flaps. So, this finding cautions that muscles without an accessory pedicle may occasionally be encountered, and preoperative CT angiography should be performed to provide accurate and reliable detail of the local vascular anatomy before the performing of surgical procedure.

Although there have been some reports of anatomic anomalies (Sainsbury \& Wagget, 1984), most anatomic studies of the gracilis muscle have indicated that the anatomy is reliable (Kumar et al., 1998). And our current study has revealed a remarkably consistent pattern of intramuscular nerve distribution within the gracilis muscle, which suits it well for functional transplantation. In the distal two thirds of the muscle, the intramuscular nerve branches ran longitudinally and parallel to the muscle fibers. This result is of clinical importance and confirms the suitability of longitudinal division for segmental functional muscle transfer, if preoperative $\mathrm{CT}$ angiography precludes the case of gracilis muscle solely supplied by a single main arterial pedicle. Just as Manktelow's anticipation (Manktelow \& Zuker, 1984), the possibility of being longitudinally separated into independent and functional neuromuscular units of the gracilis muscle makes it possible to transplant this muscle for obtaining independent thumb and finger function.

Also we found that before entering the gracilis muscle but not after the nerve has entered the muscle as Morris \& Yang description, the nerve innervating this muscle has already divided into several major branches, and then, after entering the muscle, subdivided and distributed into different parts of the muscle. When performing functional muscle flap, the operator should pay great attention to and have a clear mind of this point, because transplantation of part of the muscle with coaptation of incorrect major nerve branch which is not corresponding to this part of muscle, will lead to failure of the functional transplantation. Just as some cases in reconstruction of facial paralysis, only a part of the muscle, which is of one-third cross-sectional area of the normal gracilis, is necessary to transplant. In order to secure the function of this muscle flap, the major never branch innervating this part of muscle should be selected and coaptated correctly. So, before harvest of the flap, each major nerve branches should be stimulated separately and the corresponding portion of the muscle that contracted was observed. Through this way, the major nerve branch, which is responsible for the functional contraction of the flap, could be selected (Manktelow \& Zuker). Although the method of electrical stimulation is very necessary and useful during surgical procedure of functional flap transplantation, the innervation pattern cannot be directly visually demonstrated.
Our current research method cannot be utilized during the muscle flap transplantation by the clinician, but it can provide precise anatomic information, especially the intramuscular nerve distribution displayed direct visually, which is necessary for muscle flap transplantation procedure and can improve the understanding of the functional anatomy of the gracilis muscle by clinician, while increasing their reconstructive capabilities to gain better functional recovery of the transplanted muscle flap.

We hereby provided a method to demonstrate the intramuscular artery arborization and nerve distribution in detail by different colors in the same whole mount skeletal muscle. Although we added one more step before the Sihler's staining, no one has completed such a work up to now. We hope the introduction of this method will give inspiration to other researchers who want to perform this type of investigation. This will provide very useful information for anatomists, physiologists and clinicians to guide functional muscle flap design and innovation.

\section{ACKNOWLEDGEMENTS}

This study was funded by National Natural Science Foundation of China (31300984). The authors declare that they have no conflict of interest. Xiaochun An and Pengfei Done share senior authorship of this work.

AN, X.; DONG, P.; QU, X. \& LI, S. Demostración de la distribución intramuscular de la arteria y nervio del músculo gracil mediante diferentes colores. Int. J. Morphol., 34(3) :1034-1038, 2016.

RESUMEN: El objetivo de este estudio fue describir en detalle la distribución intramuscular de la arteria y el nervio del músculo grácil por diferentes colores en un solo montaje. Se realizó inyección de látex rojo en la arteria ilíaca externa en 14 cadáveres humanos frescos. Dos semanas más tarde se retiraron 28 músculos grácil de los cadáveres y se realizó un conteo del número de pedículos arteriales de cada muestra. Las muestras de músculo se fijaron en formalina al $10 \%$ durante 4 semanas para los procedimientos de tinción de Sihler. Al término de todos los procedimientos, el músculo grácil parecía casi transparente, y las ramas extra e intramusculares de las arterias y los nervios, incluso los terminales, se observaron en azul y rojo oscuro por separado. Dos de los 28 especímenes presentaron por pedículo arterial principal único, 14 muestras un pedículo arterial principal y un pedículo accesorio, 8 de las muestras un pedículo principal y dos pedículos accesorios, mientras que 4 muestras un pedículo arterial principal y tres pedículos accesorios. Aunque el número de los pedículos arteriales era inconsistente, las ramas de la arteria intramuscular se anastomosaban entre sí y formaban un sistema arterial conjunto en todos los especímenes. El nervio que inerva el músculo grácil se 
encontró dividido en dos o tres ramos principales, dirigidos distalmente e inervaron los dos tercios distales del músculo, mientras que otro discurre longitudinalmente y en paralelo a las fibras musculares. Encontramos que el patrón de inervación fue notablemente consistente de un especimen a otro. Este estudio proporciona información muy detallada y útil para los anatomistas, fisiólogos y cirujanos. Además, también se proporcionó un método innovador para demostrar la distribución intramuscular de la arteria y el nervio en un mismo músculo, entero, y con diferentes colores.

PALABRAS CLAVE: Distribución intramuscular ; Arteria; Nervio; Musculo grácil.

\section{REFERENCES}

Cavadas, P. C.; Sanz-Giménez-Rico, J. R.; Landín, L. \& MartínezSoriano, F. Segmental gracilis free flap based on secondary pedicles: anatomical study and clinical series. Plast. Reconstr. Surg., 114(3):684-91, 2004.

Krimmer, H.; Hahn, P. \& Lanz, U. Free gracilis muscle transplantation for hand reconstruction. Clin. Orthop. Relat. Res., (314):13-8, 1995.

Kumar, V. P.; Liu, J.; Lau, H. K.; Pereira, B. P.; Shen, Y. \& Pho, R. W. Neurovascular supply of the gracilis muscle: a study in the monkey and human. Plast. Reconstr. Surg., 101(7):1854-60, 1998.

Liem, R. S. \& Douwe van Willigen, J. In toto staining and preservation of peripheral nervous tissue. Stain Technol., 63(2):113-20, 1988

Macchi, V.; Vigato, E.; Porzionato, A.; Tiengo, C.; Stecco, C.; Parenti, A.; Morra, A.; Bassetto, F.; Mazzoleni, F. \& De Caro, $\mathrm{R}$. The gracilis muscle and its use in clinical reconstruction: an anatomical, embryological, and radiological study. Clin. Anat., 21(7):696-704, 2008.

Magden, O.; Tayfur, V.; Edizer, M. \& Atabey, A. Anatomy of gracilis muscle flap. J. Craniofac. Surg., 21(6):1948-50, 2010.

Manktelow, R. T. \& Zuker, R. M. Muscle transplantation by fascicular territory. Plast. Reconstr. Surg., 73(5):751-7, 1984.

Melenhorst, J.; Koch, S. M.; van Gemert, W. G. \& Baeten, C. G. The artificial bowel sphincter for faecal incontinence: a single centre study. Int. J. Colorectal Dis., 23(1):107-11, 2008.

Morris, S. F. \& Yang, D. Gracilis muscle: arterial and neural basis for subdivision. Ann. Plast. Surg., 42(6):630-3, 1999.

Mu, L. \& Sanders, I. Sihler's whole mount nerve staining technique: a review. Biotech. Histochem., 85(1):19-42, 2010.

Revenaugh, P. C. \& Byrne, P. J. Gracilis microneurovascular transfer for facial paralysis. Facial Plast. Surg., 31(2):134-9, 2015.

Sainsbury, J. R. \& Wagget, J. An absent gracilis--case report. Br. J. Clin. Pract., 38(2):72, 1984.

Schoeller, T.; Meirer, R.; Gurunluoglu, R.; Piza-Katzer, H. \& Wechselberger, G. Gracilis muscle split into two free flaps. $J$. Reconstr. Microsurg., 19(5):295-8, 2003.

Taylor, G. I.; Cichowitz, A.; Ang, S. G.; Seneviratne, S. \& Ashton, M. Comparative anatomical study of the gracilis and coracobrachialis muscles: implications for facial reanimation. Plast. Reconstr. Surg., 112(1):20-30, 2003.

Won, S. Y.; Rha, D. W.; Kim, H. S.; Jung, S. H.; Park, E. S.; Hu, K. S. \& Kim, H. J. Intramuscular nerve distribution pattern of the adductor longus and gracilis muscles demonstrated with Sihler staining: guidance for botulinum toxin injection. Muscle Nerve, 46(1):80-5, 2012.

Wu, B. L. \& Sanders, I. A technique for demonstrating the nerve supply of whole larynges. Arch. Otolaryngol. Head Neck. Surg., 118(8):822-7, 1992.

Zuker, R. M.; Bezuhly, M. \& Manktelow, R. T. Selective fascicular coaptation of free functioning gracilis transfer for restoration of independent thumb and finger flexion following Volkmann ischemic contracture. J. Reconstr. Microsurg., 27(7):439-44, 2011.

Correspondence to:

Xiao-Chun An, M.D., Ph.D.

Department of Orthopaedics

Yantai Affiliated Hospital

Binzhou Medical University

Yantai City

Shandong Province

CHINA.

Phone: +865354770831

Fax : +86 5356913297

Email: axcbzmc@163.com

Received: 22-03-2016

Accepted: 04-07-2016 